\title{
A representação do sertão e o "espaço da saudade" na poética de Jessier Quirino
}

\section{Thaís Duarte Silvério ${ }^{I}$}

\author{
Cristiano Cezar Gomes da Silva
}

Resumo: O presente artigo busca compreender como o sertão, tema recorrente em importantes obras literárias brasileiras, a exemplo dos clássicos "Os Sertões "III "Vidas secas" "IV, e "Grande sertão: veredas"V" é representado na composição dos poemas de Jessier Quirino, cuja tessitura dá-se, diversas vezes, através de uma "linguagem matuta" que se mistura à forte presença de neologismos e aos denominados "espaços da saudade". Tais espaços ora se dão como referências geográficas, elaboração de cenários interioranos, menções à indumentária e à culinária nordestinas, ora se dão como o próprio espaço do poema, da leitura e escuta dos textos, diversas vezes voltados para um rememorar ou (re)inventar de determinados passados. Interessa-nos compreender como determinadas imagens representadas no poema Zé Qualquer e Chica Boa ${ }^{V I}$, contribuem para construir identidades para personagens sertanejas e como contribui para reforçar uma imagem estereotipada da região.

Palavras-chave: Espaços da saudade, Jessier Quirino, representação, memória, sertão.

\section{Backland representation and the "nostalgia space" in Jessier Quirino's poetry}

Abstract: This paper aims to comprehend the ways that backlands, a recurrent theme in important Brazilian literary pieces as the classics "Rebellion in the backlands", "Barren lives" and "The Devil to Pay in the Backlands", are represented in the composition of Jessier Quirino's poems, whose structures are often arranged through a "bumpkin language" which is combined to a strong presence of neologisms and the called "nostalgia space". These spaces sometimes are created through geographic references, countryside sceneries elaboration, northeastern clothing and cuisine mentions, and sometimes are created through the space of the poem itself, of reading and listening to the texts which are often focused on a remembrance or (re)invention of certain past time. We are interested in comprehend how certain images represented in the poems Zé Qualquer (Average Joe, free translation) and Chica Boa (Good Chica, free translation) contribute to the construction of backland characters' identities and how they contribute to reinforce a stereotyped image of the region.

Keywords: Nostalgia spaces, Jessier Quirino, representation, memory, backland.

Artigo recebido em 06/04/2019 e aprovado em 27/05/2019. 


\title{
A REPRESENTAÇÃO DO SERTÃO E O "ESPAÇO DA SAUDADE" NA POÉTICA DE JESSIER QUIRINO
}

\author{
THAÍS DUARTE SILVÉRIO E CRISTIANO CEZAR GOMES DASILVA
}

\section{Introdução}

O presente artigo busca compreender como o sertão, tema recorrente em importantes obras literárias brasileiras, a exemplo dos clássicos Os sertões, de Euclides da Cunha; Vidas secas, de Graciliano Ramos; e Grande sertão: Veredas, de Guimarães Rosa (ainda que este falando mais especificamente sobre o sertão mineiro), é representado como cenário privilegiado pelo poeta paraibano Jessier Quirino na composição de seus poemas, cuja tessitura dá-se, diversas vezes, através de uma "linguagem matuta", que se mistura à forte presença de neologismos e ao que o historiador Durval Muniz de Albuquerque Júnior ${ }^{\mathrm{VII}}$ denomina como "espaços da saudade".

Tais espaços ora se dão como referências geográficas, elaboração de cenários interioranos, menções à indumentária e à culinária nordestinas, ora se dão como o próprio espaço do poema, da leitura e escuta dos textos quirinianos, voltados diversas vezes para um rememorar ou (re)inventar de passados, no presente da enunciação poética. No caso do poeta, esses poemas criam tempos e personagens que permitem ao leitor experimentar breves incursões no universo sertanejo e nordestino, no cotidiano dos "sertões", provocando, em certa medida, sensações de déjà $v u$, embora muitos não tenham vivido experiências próximas às evidenciadas nos textos. Em decorrência do poder de evocação da poesia, tais definições não excluem de mira aqueles leitores que só tiveram vivências urbanas. Nesse ponto, também, os espaços da saudade, como pretendemos mostrar, se fazem mais presentes: sejam nas memórias evocadas naqueles que viveram realidades semelhantes às relatadas nos poemas, sejam nas memórias elaboradas para aqueles que só vivem ou viveram tais realidades exatamente porque leram ou ouviram poemas como os de Jessier Quirino.

"Arquiteto por profissão, poeta por vocação e matuto por convicção", é o modo pelo qual o poeta apresenta-se para o público leitor e espectador. Autor de alguns livros, entre eles Paisagem de interior ${ }^{V I I}$, Agruras da lata d'água $^{I X}$, Prosa morena $^{X}$ e Berro Novo ${ }^{X I}$, Jessier foi tema de vestibulares na Paraíba e costuma apresentar-se em feiras literárias, teatros e centros de convenções, além de ter participado de programas midiáticos televisivos locais e nacionais. Apesar de utilizar uma linguagem matuta para declamar seus poemas e "causos", imbricando-se com neologismos dos mais inusitados, o poeta reúne públicos distintos, letrados e iletrados, que dialogam quando o assunto é poesia.

$\mathrm{O}$ processo de feitura dos poemas junta-se à sua recepção num jogo que guarda algumas particularidades muito específicas, quer seja pelos espaços que frequenta, quer seja pelos meios de que se utiliza para circular sua poesia. Quirino configura-se como uma versão atualizada dos antigos cantadores de feira, aqueles que reuniam ao redor de si diversos curiosos e simpatizantes, ao declamar e cantar cordéis, obedecendo a métricas e rimas precisas. Contudo, os poemas quirinianos parecem, muitas vezes, apontar para um lugar simbólico, que Albuquerque Júnior ${ }^{\mathrm{XII}}$ chamará de "invenção do Nordeste". Essa "invenção" contemplou não somente a literatura, mas as músicas, as telenovelas e o cinema brasileiros, que passaram a enxergar o Nordeste, até então considerado Norte, sob a ótica da seca mediante uma representação simbólica. 


\title{
A REPRESENTAÇÃO DO SERTÃO E O "ESPAÇO DA SAUDADE" NA POÉTICA DE JESSIER QUIRINO
}

\section{THAÍS DUARTE SILVÉRIO E CRISTIANO CEZAR GOMES DASILVA}

Por muitos anos a seca foi considerada o pilar da identidade nordestina, ainda que esse fenômeno fosse característico de regiões semiáridas como o sertão. Diversos literatos e compositores escreveram sobre as agruras da falta d'água e aos poucos esse lugar foi se (re)construindo a partir de um imaginário pitoresco, onde o sertanejo resumia-se a alguém plano, sem complexidades, pertencente a uma terra martirizada e infértil. Esse imaginário foi decisivo para a "invenção do Nordeste".

Assim, é necessário entender o sertão desenhado pelo poeta, observando alguns dos processos simbólicos pelos quais passou o Nordeste, aproximando essa visão das representações nos poemas. Nesse sentido, buscamos compreender por que esse tema foi tão recorrente nos cordéis, pelejas e cantorias, e de que modo a circulação desses poemas nos grandes centros do Brasil serviu para prefigurar e denunciar (ou cristalizar, em certos casos) um Nordeste cujas marcas principais eram (e muitas vezes são) a miséria e a fome. Embora essa região tenha a segunda maior população do Brasil, possua uma cultura rica e diversificada e seja o berço de figuras importantes da literatura, a exemplo do já citado Graciliano Ramos, Ariano Suassuna, Rachel de Queiroz, João Cabral de Melo Neto, dentre tantos outros, não é raro que seja identificada, ainda hoje, como o protótipo de região pobre, que passa por severas secas e que tem um povo sofrido e pouco alfabetizado. No poema Caderneta de Matuto ${ }^{\text {XIII, }}$ Jessier constrói uma representação desse quadro:

\author{
Foi seca batendo palma \\ Na porta do milharal \\ E o cumpade de arranco \\ Fugindo pra capital \\ Deixando um quintal rachado \\ Com lençóis enferrujados \\ Rangendo pelo varal ${ }^{\mathrm{XIV}}$.
}

Apesar de esse estigma ganhar uma nova roupagem com o passar dos anos, grande parte da população que nunca visitou o Nordeste, ainda se depara com personagens caricaturados, com sotaques acentuados e estigmatizados e com pouca ou nenhuma formação escolar nos mais variados programas de televisão. Essas personagens parecem apontar para extremos baseados em figuras folclorizadas, a exemplo de Lampião e Antônio Conselheiro.

Desse modo, tal discussão, acerca dos "círculos" culturais, pode ter na literatura dita popular um espaço rico de desenvolvimento. Nesse sentido, para analisar a obra quiriniana neste trabalho, trouxemos à baila os conceitos de identidade e cultura, a partir de Stuart Hall ${ }^{\mathrm{XV}}$ e Clifford Geertz ${ }^{\mathrm{XVI}}$. Para fundamentar o conceito de memória e memória coletiva, tomamos como aporte teórico Maurice Halbwachs $^{\mathrm{XVII}}$, assim como Albuquerque Júnior ${ }^{\mathrm{XVIII}}$, mediante a expressão/noção "espaços da saudade", que orientará parte do trabalho. A fim de aprofundarmos a discussão acerca de representação, poesia escrita e falada e poesia popular e erudita, recorremos às obras de Sandra Jatahy Pesavento ${ }^{\mathrm{XIX}}$, Mark Curran ${ }^{\mathrm{XX}}$ e Aderaldo Luciano $^{\mathrm{XXI}}$, respectivamente.

No intuito de compreendermos como se dá a construção imagética a qual Jessier Quirino se filia para compor seus "causos" e poesias, analisamos recortes do poema Zé Qualquer e Chica Boa ${ }^{X X I I}$. Assim, interessou-nos analisar quais estratégias 


\title{
A REPRESENTAÇÃO DO SERTÃO E O "ESPAÇO DA SAUDADE" NA POÉTICA DE JESSIER QUIRINO
}

\author{
THAÍS DUARTE SILVÉRIO E CRISTIANO CEZAR GOMES DASILVA
}

Quirino escolheu para compor os espaços físicos e as personagens do poema, utilizando-se de determinados recursos e imagens que muitas vezes pareciam existir apenas na licença poética. Buscamos entender como, em sua poesia, certas descrições e projeções desenham cenários e forjam noções identitárias específicas, marcadas por um saudosismo recorrente. Nessa direção, realizamos um trabalho de natureza qualitativa e de cunho bibliográfico a partir do poema do cantador, ao tempo que utilizamos como aporte teórico os autores elencados acima.

\section{Sertão, literatura e identidade}

Não é novidade que o sertão tenha servido como cenário para importantes obras da literatura brasileira, como citado anteriormente. Segundo Albuquerque Júnior,

\begin{abstract}
A seca surge na literatura como aquele fenômeno detonador de transformações radicais na vida das pessoas, desorganizando as famílias social e moralmente. É responsabilizada, inclusive, pelos conflitos sociais na região, pela existência do cangaceiro e do beato, naturalizando-se as questões sociais. Se o sertão pega fogo, é graças ao sol inclemente ${ }^{\mathrm{XIII}}$.
\end{abstract}

Ainda segundo o autor, é nesse período que surge na literatura o chamado "romance de trinta", que instituiu como principais temas regionais o coronelismo justaposto ao jagunço e à seca, a decadência da sociedade açucareira, o beatismo e messianismo e o cangaço. Esse gênero abordava diversas realidades do Nordeste, contribuindo para incrementar um quadro ainda desconhecido para muitas regiões do país. Os autores passaram a denunciar em seus livros determinadas condições às quais se sujeitavam os nordestinos durante a alta estiagem. Contudo, se por um lado esses livros ajudaram a alterar a imagem do sertanejo como um sujeito plano, sem complexidades psicológicas, eles também ajudaram na elaboração de outros imaginários, especialmente para quem só tinha contato com a região através desses livros. Como uma via de mão dupla, é possível ver tais livros tanto como obras de arte e denúncia quanto como reforçadores ou instauradores de outras imagens e identidades.

Ainda em relação à seca, além da literatura, esse período atraiu produtores e realizadores de filmes, programas de televisão e documentários. Para Mark Curran $^{\mathrm{XXIV}}$, foi o tema mais representativo das tragédias na região. Nos grandes centros, as imagens que circulavam do Nordeste estavam atreladas à miséria, e com ela a necessidade de migrar. Seja na literatura considerada de massa, seja na literatura erudita, o drama do retirante sertanejo ganharia destaque nacional.

Embora os períodos de longa estiagem tenham ampliado as produções culturais e artísticas no Nordeste, perpassando não somente a literatura, mas a música, o cinema, a televisão e a pintura, por exemplo, o sertão não pode ser definido apenas pelos seus limites fronteiriços, assim como não pode ser representado somente pela ótica da seca. O sertão é uma espacialidade que precisa ser entendida como um todo, perpassando os costumes, as crenças, até sua religiosidade. Para entendê- lo é preciso adentrar à história, aos anos de esquecimento, às brigas políticas, ao descaso. É 


\section{A REPRESENTAÇÃO DO SERTÃO E O "ESPAÇO DA SAUDADE" NA POÉTICA DE JESSIER QUIRINO}

\section{THAÍS DUARTE SILVÉRIO E CRISTIANO CEZAR GOMES DASILVA}

necessário compreender os discursos, a simbologia, a cultura, romper estereótipos, para então tentar decifrar sua gente e conhecer o que está por trás do imaginário que o reduz à seca. Para Geertz (2008), apenas o nativo é capaz de fazer uma descrição primária do lugar a qual fincou suas raízes, ou seja, a partir desse pressuposto, somente pela ótica do sertanejo conseguiríamos compreender toda complexidade desse lugar. Magalhães ${ }^{\mathrm{XXV}}$ acrescenta-nos que o sertão é:

[...] o vasto campo da criação, a zona pastoril caracterizada. Nessa natureza híspida, fora do contato da civilização do litoral, sem vias de comunicação, nem meios fáceis de transporte, segregados nas condições físicas mais hostis, se diferenciou um tipo étnico vigoroso. É o sertanejo, o homem heróico, flagelado pelas fatalidades climatéricas e sociais, que nos longínquos rincões adustos, obscuro e grande, resiste à natureza ingrata, retemperando as energias da raça histórica em formação ${ }^{\mathrm{XXVI}}$.

No entanto, o mesmo sertão da seca, da sazonalidade dos rios, da privação e do solo infértil, dá lugar ao verde das terras, às arvores frutíferas, ao gado gordo e leiteiro nos períodos de chuva. A água que corre pelos vales e enche as cacimbas, deixa a mesa farta e o sertanejo repleto de esperança. Agamenon Magalhães reitera, no livro $O$ Nordeste brasileiro, que "do homem forte dos sertões não se pode esperar mais do que a resistência heróica que há quatro séculos, porfiadamente mantém sem tréguas, nem desfalecimentos, dorso nu, cavando a terra, tendo uma só esperança, é Deus" XXVII

É a partir da representação do sertanejo que analisaremos a personagem Zé Qualquer segundo a ótica de Jessier Quirino. Nessa direção, trazendo à baila o conceito de representação, a partir da história cultural a qual Pesavento ${ }^{\text {XVIIII }}$ se filia, acreditamos, assim como a autora, que "representar é, pois, fundamentalmente estar no lugar de"XXIX algo ou alguém, cujo significado "desliza pelos regimes de verossimilhança e de credibilidade, e não de veracidade"XXX . O modo como o sertanejo tem sido representado nos livros de grande circulação, assim como nas poesias, sejam elas consideradas clássicas ou as publicadas em folhetos, como as de cordel, a qual Quirino parece dialogar, soma-se ao interesse de conceituar não somente a representação, mas o simbólico e o imaginário. Sobre esse último, Pesavento acrescenta-nos que "o imaginário comporta crenças, mitos, ideologias, conceitos, valores, é construtor de identidades e exclusões, hierarquiza, divide, aponta semelhanças e diferenças no social. Ele é um saber fazer que organiza o mundo, produzindo a coesão ou o conflito",XXXI.

Partindo do pressuposto que Jessier Quirino elabora tempos e personagens simbólicos que permitem ao leitor experimentar sensações nostálgicas, analisaremos o conceito de memória a partir das perspectivas de Maurice Halbwachs, que acrescenta-nos que as "lembranças permanecem coletivas e nos são lembradas por outros, ainda que trate de eventos em que somente nós estivemos envolvidos e objetos que somente nós vimos. Isso acontece porque jamais estamos sós"XXXII.

Para além dessas trilhas, que consideramos as principais de nosso trabalho, outras vias de investigação se insinuam como possíveis. Ainda que haja uma recepção relativamente massiva dos poemas quirinianos, não cabe a esta pesquisa intitular sua obra como pertencente à literatura de massa, que tem características, 


\title{
A REPRESENTAÇÃO DO SERTÃO E O "ESPAÇO DA SAUDADE" NA POÉTICA DE JESSIER QUIRINO
}

\section{THAÍS DUARTE SILVÉRIO E CRISTIANO CEZAR GOMES DASILVA}

meios de circulação e público específicos. Os poemas quirinianos parecem ocupar um lugar mais híbrido, ora com um pé nas mídias de comunicação, ora com um pé na tradição rica da poesia do Nordeste, o que, contudo, não nos autoriza a pensá-lo essencialmente como popular, consideramos, assim como Ortiz ${ }^{\text {XXXIII }}$, que a cultura popular é heterogênea. Nesse ponto, também compartilhamos com a perspectiva de Aderaldo Luciano ${ }^{\text {XXIV }}$ que tece uma crítica sobre a distinção entre popular e erudito na literatura, assemelhando-se à perspectiva de Canclini ${ }^{X X X V}$ acerca dos conceitos de erudito, popular e massivo. Segundo Luciano,

Essa distinção, segundo percebemos, reside na forma preconceituosa e excludente com que as elites intelectuais sempre trataram as produções que não saíssem de suas lides ou que não seguissem os seus ditames. Popular seria aquela poesia produzida pelo "povo", os não letrados, os trabalhadores rurais, os habitantes dos guetos $\mathrm{XXXVI}$.

Já, a partir da direção apontada por Bosi ${ }^{X X X I I}$, acreditamos que "nem a cultura popular tradicional nem a cultura erudita moderna constroem-se a partir de um regime de produção em série com linhas de montagem e horários regulados mecanicamente"XXXVIII . E é, segundo essa perspectiva, que o poeta transita entre a linguagem culta e a linguagem matuta, tendo a segunda tornado-se uma característica do cantador. Sobre a poesia matuta, Tavares ${ }^{\mathrm{XXXX}}$ acresecenta: "tenho feito restrições ao uso do „poema matuto "e quando ele me parece deformar desnecessariamente o modo de falar das pessoas" $\mathrm{XL}$. No entanto, as poesias quirinianas parecem convergir também para o gracejo, artimanha risível utilizada pelo poeta para retratar o cotidiano dos sujeitos intitulados por ele de matutos, levando os leitores e espectadores a darem boas gargalhadas. Apesar de o riso estar presente mais que a crítica social, como no caso das poesias de Patativa do Assaré, por exemplo, Jessier Quirino também leva o leitor a refletir. No poema Zé Qualquer e Chica Boa, Quirino faz uma crítica social à invisibilidade daqueles que estão na base da pirâmide. O Qualquer do Zé, cujo poema sugere, "não é qualquer Qualquer não"XLI, pois Quirino utiliza propositadamente o nome e o sobrenome da personagem principal para instigar o leitor à reflexão quanto aos usos corriqueiros dos "seus Zés" e por que não "donas Marias" ou "Chicas" para referirem-se ao modo como as pessoas com poder aquisitivo baixo, com pouca ou nenhuma formação escolar, são negligenciadas e invisibilizadas pela sociedade e assim chamadas. Ao definir a personagem Zé Qulaquer, Quirino assim o descreve:

\author{
É cabôco elefantado \\ Que não tem medo de cruz \\ Que fita o sol faiscando \\ Dez mil peixeiras de luz \\ O Zé que assim se conduz \\ Nas brenhas deste sertão \\ O Zé Ninguém, Zé Qualquer \\ Mas o Qualquer desse Zé \\ Não é qualquer qualquer não ${ }^{\mathrm{XLII}}$
}

No trecho anterior, vemos a descrição de uma personagem retomando o imaginário materializado no início do século passado, quando Euclides da Cunha 


\title{
A REPRESENTAÇÃO DO SERTÃO E O "ESPAÇO DA SAUDADE" NA POÉTICA DE JESSIER QUIRINO
}

\section{THAÍS DUARTE SILVÉRIO E CRISTIANO CEZAR GOMES DASILVA}

define o sertanejo como "antes de tudo, um forte"XLIII. Há uma ressignificação da força desse sertanejo ao ser representado na personagem Zé Qualquer, metaforizado no poema como um "cabôco elefantado", ou seja, aquele que se agiganta diante das agruras e aridez do sertão, corajoso por que "não tem medo de cruz", possuindo "dez mil peixeiras de luz", no seu enfrentamento quase quixotesco com o "sol faiscando". Sendo assim, no âmbito da poesia quiriniana, a construção simbólica da valentia do sertanejo, tão presente no imaginário coletivo perpassando o sertão do homem forte, homem valente e que "não é qualquer qualquer não".

Ainda no poema analisado, observamos Quirino (re)construir definições identitárias mediante a personagem que parecem ser o protótipo do homem "matuto", que resguarda tradições, e resiste muito pelo simples fato de ser como é, às mudanças da modernidade. Num outro trecho do poema, percebemos a predominância do verbo ser, empregado na segunda pessoa do plural, vós, o que nos faz compreender que a personagem Zé Qualquer representa todos aqueles que, de algum modo, se identificam com a bravura e perseverança do homem sertanejo e nordestino. Vejamos:

\author{
Sois bafo de cuscuzeira \\ Sois caldo de milho quente \\ Sois a canjica do milho \\ Sois milho pessoalmente \\ $\mathrm{Tu}$ sois forte no batente \\ Tu sois como milho assado \\ Se não for bem mastigado \\ Sai inteirinho da gente. ${ }^{\text {XLIV }}$
}

Podemos ver acima como o sertanejo é mais uma vez metaforizado no poema como o homem forte e resiliente, comparado, através de analogia, ao milho, alimento bem presente na culinária do sertão, pois de fácil cultivo e plantio, tradicionalmente integra a alimentação por seu baixo custo, grande valor nutricional e diversificada variação em seu uso, como descrito no poema, quer seja no cuscuz ou no caldo, quer seja na canjica ou assado, "pessoalmente". Dessa maneira, temos na metáfora do milho, ligado às tradições locais, uma forma do poeta construir e narrar a força do sertanejo. O poeta dá vida a esse sertanejo, mediante a personagem Zé Qualquer, a partir da referenciação a elementos arraigados à cultura nordestina: desde aquilo que é trabalhado pela

mão humana, como exemplo, o milho, que se transforma em canjica etc., àquilo que não necessita do humano para existir, o ninho de carcará, como veremos a seguir, relacionando, assim, o sertanejo ao seu lugar de modo estreito, como se um fosse feito do outro.

\author{
Sois umbuzeiro de estrada \\ Sois ninho de carcará \\ Sois folha seca, sois galho \\ Sois fulô de se cheirar \\ Sois fruto doce e azedo \\ Sois raiz que logo cedo \\ Quer terra pra se enfiar. ${ }^{X L V}$
}

Cadernos do Tempo Presente, São Cristóvão-SE, v. 10, n. 01, p. 25-36, jan./jul. 2019| http://www.seer.ufs.br/index.php/tempo 


\title{
A REPRESENTAÇÃO DO SERTÃO E O "ESPAÇO DA SAUDADE" NA POÉTICA DE JESSIER QUIRINO
}

\author{
THAÍS DUARTE SILVÉRIO E CRISTIANO CEZAR GOMES DASILVA
}

No trecho acima, temos o sertanejo comparado à paisagem e vegetação do sertão. O umbuzeiro, "árvore sagrada do sertão"XLVI, como assinalado por Euclides da Cunha, em Os Sertões, espécie resistente à sequidão do lugar, pequena, mas abundante em sua folhagem e em sua robustez, produz frutos que alimentam a população sertaneja. Na descrição da obra euclidiana, "se não existisse o umbuzeiro aquele trato de sertão, tão estéril (...) estaria despovoado"XLVII . Em uma releitura euclidiana, Quirino ressignifica o clássico da literatura brasileira, ao comparar a personagem Zé Qualquer ao umbuzeiro de estrada, retomando ditos e escritos consagrados e canonizados nas letras brasileiras.

Ainda vemos uma analogia do sertanejo à raiz que se aprofunda no solo para buscar nutrientes à árvore, bem como sustentação para ficar de pé, acumula uma reserva de nutrientes e robustez desafiadora aos longos períodos de estiagem, raiz "que logo cedo quer terra para se enfiar", no poema de Jessier Quirino. Já em Euclides da Cunha, o umbuzeiro "representa o mais frisante exemplo de adaptação da flora sertaneja"XLVIII, a resistência está na força de suas raízes, pois "até se preparar para a resistência e reagindo, por fim, desafiando as secas duradouras, sustentando-se nas quadras miseráveis mercê da energia vital que economiza nas estações benéficas das reservas guardadas em grande cópia nas raízes."XLIX

Quirino também utiliza a metáfora do ninho do carcará, lugar de segurança dessa espécie de pássaro presente na região sertaneja, construído na bainha das árvores grandes e altas para minimizar a possibilidade de quedas do ninho e de ataques de outras aves. Portanto, é essa a figura

forte do sertanejo, ressignificada por Quirino em sua poesia, na medida em que o poeta (re)constrói mediante elementos da natureza e da paisagem do sertão.

O Zé que se aprisiona
Aos cacos velhos da enxada
Que nasce herdeiro do nada
E qualquer lado é seu caminho
Medalhas, são seus espinhos
Quedas de bois são batalhas
Seus braços, duas cangalhas
De taipa e barro é seu ninho.

Noutra direção, observamos um sertanejo representado pela vida dura e de poucos recursos, um retrato da miséria e da pobreza simbolizadas, para Quirino, "aos cacos velhos da enxada, que nasce herdeiro do nada", como a despossessão de Zé Qualquer, representação quiriniana do "homem permanentemente fatigado"LI euclidiano. A aspereza da vida, no poema, se faz representar nos espinhos como medalhas de um vencedor por ser resistente, forte e perseverante em terreno tão hostil àqueles forasteiros desconhecedores dos seus segredos e encantos do sertão.

Ampliando o leque de representações acerca do sertanejo, Quirino ressignifica, ainda, a religiosidade local, ao elaborar a imagem de Zé Qualquer como "devoto de padre Ciço" e ao descrevê-lo como "matuto rezador", vejamos:

Sois um Zé Qualquer do mato

Cadernos do Tempo Presente, São Cristóvão-SE, v. 10, n. 01, p. 25-36, jan./jul. 2019|

http://www.seer.ufs.br/index.php/tempo 


\title{
A REPRESENTAÇÃO DO SERTÃO E O "ESPAÇO DA SAUDADE" NA POÉTICA DE JESSIER QUIRINO
}

\section{THAÍS DUARTE SILVÉRIO E CRISTIANO CEZAR GOMES DASILVA}

\author{
Provador de amargor \\ Tu sois urro, sois maciço \\ Devoto do padre Ciço \\ Sois matuto rezador \\ O Zé Qualquer em pessoa Marido de Chica Boa \\ $\mathrm{O}$ teu verdadeiro amor. ${ }^{\mathrm{LII}}$
}

Dessa maneira, há uma referenciação à fé do sertanejo, às suas práticas de religiosidade, ligada à matriz católica, porém ligada ao popular religioso de massa, principalmente no sertão nordestino. Percebemos uma aproximação mediante uma ressignificação da descrição dessa mesma religiosidade encontrada na obra euclidiana acerca de Antônio Conselheiro:

Era o profeta, o emissário das alturas, transfigurado por ilapso estupendo, mas adstrito a todas as contingências humanas, passível do sofrimento e da morte, e tendo uma função exclusiva: apontar aos pecadores o caminho da salvação. Satisfez-se sempre com este papel de delegado dos ceús. ${ }^{\text {LII }}$

Se em Euclides da Cunha, vemos a descrição messiânica de Conselheiro, em Jessier Quirino, temos a figura simbólica do padre Ciço como representação da expressão de fé católica, salvífica e de massa, arraigada no imaginário do sertão e do sertanejo. Uma correlação possível, uma materialização da ressignificação do imaginário e memória coletiva.

\section{Conclusão}

A poesia quiriniana, embora transite por outros vieses que não sejam interioranos, rurais e sertanejos, constitui-se em grande parcela a partir da identificação do poeta com o sujeito matuto. Nesse ponto, Jessier apresenta-se como uma espécie de observador participante, que, embora letrado, opta por um linguajar que preserva, em certos casos, expressões caídas no esquecimento. Assim, Quirino recupera, nos poemas, noções identitárias da fala dessas personagens que acabaram se perdendo com a influência midiática e massiva. Esse processo de transição das identidades, que, segundo Hall ${ }^{\mathrm{LIV}}$, deixaram de ser unificadas e homogêneas e tornaram-se descentradas, fragmentadas e por que não líquidas, junta-se ao fato de que essa poesia também contribui para a (re)construção de uma memória coletiva e individual da comunidade a qual esse sujeito está inscrito. Esse lugar de memória que transita em grande parte pelas expressões arcaicas ou pouco conhecidas utilizadas pelo poeta no poema Zé Qualquer e Chica Boa ${ }^{L V}$, por exemplo, ora transita na individualidade ora finca-se no coletivo e é nesse ponto que os leitores que nunca estiveram fisicamente no sertão, a não ser por poesias como as de Quirino, são convidados a adentrar a esse "espaço da saudade" que tanto pode ser o espaço propriamente físico ou um espaço simbólico e imaginário representado a partir da literatura, das músicas e dos filmes. 


\section{A REPRESENTAÇÃO DO SERTÃO E O "ESPAÇO DA SAUDADE" NA POÉTICA DE JESSIER QUIRINO}

\section{THAÍS DUARTE SILVÉRIO E CRISTIANO CEZAR GOMES DASILVA}

\section{Notas}

I Mestranda do Programa de Pós-Graduação em Dinâmicas Territoriais e Cultura, da Universidade Estadual de Alagoas - UNEAL. E-mail: thaisduarte-silverio@hotmail.com. Versão deste texto foi apresentada em formato de comunicação durante o VIII Congresso Internacional Interdisciplinar em Sociais e Humanidades, da Associação Nacional de Pesquisa e Pós-Graduação em Sociais e Humanidades.

II Doutor em Letras pela Universidade Federal da Paraíba. Professor Permanente do Programa de PósGraduação em Dinâmicas Territoriais e Cultura, da Universidade Estadual de Alagoas - UNEAL. E-mail: cristianocezar.pe@bol.com.br.

III Obra publicada originalmente em 1902, por Euclides da Cunha.

IV Obra publicada originalmente em 1938, por Graciliano Ramos.

V Obra publicada originalmente em 1956, por Guimarães Rosa.

VI Obra publicada originalmente em 2001, por Jessier Quirino.

VII ALBUQUERQUE JÚNIOR, Durval Muniz de. A invenção do nordeste e outras artes / Durval Muniz de Albuquerque Júnior; prefácio de Margareth Rago. - 5. ed. - São Paulo: Cortez, 2011.

VIII TAVARES, Bráulio. Mestre Jessier. In: QUIRINO, Jessier. Paisagem de interior. Recife: Bagaço, 1996.

IX TAVARES, Bráulio. Mestre Jessier. In: QUIRINO, Jessier. Paisagem de interior. Recife: Bagaço, 1996.

${ }^{X}$ QUIRINO, Jessier. Prosa morena. Recife: Bagaço, 2001.

XI QUIRINO, Jessier. Berro Novo. Recife: Bagaço, 2009.

XII ALBUQUERQUE JÚNIOR, Durval Muniz de. A invenção do nordeste e outras artes / Durval Muniz de Albuquerque Júnior; prefácio de Margareth Rago. - 5. ed. - São Paulo: Cortez, 2011.

XIII QUIRINO, Jessier. Prosa morena. Recife: Bagaço, 2001.

XIV QUIRINO, Jessier. Prosa morena. Recife: Bagaço, 2001. p. 63.

XV HALL, Stuart. A identidade cultural na pós-modernidade. 10. ed. Rio de Janeiro: DP\&A, 2005.

XVI GEERTZ, Clifford. A interpretação das culturas. 1. ed., reimpressão. Rio de Janeiro: LTC, 2008.

XVII HALBWACHS, Maurice. A memória coletiva. Tradução de Beatriz Sidou. 2. ed. São Paulo:

Centauro, 2013.

XVIII ALBUQUERQUE JÚNIOR, Durval Muniz de. A invenção do nordeste e outras artes / Durval Muniz de Albuquerque Júnior; prefácio de Margareth Rago. - 5. ed. - São Paulo: Cortez, 2011.

XIX PESAVENTO, Sandra Jatahy. História \& história cultural. 2. ed. Belo Horizonte: Autêntica, 2012.

XX CURRAN, Mark. Retratos do Brasil em Cordel. Cotia, SP: Ateliê Editorial, 2011.

XXI LUCIANO, Aderaldo, 1964. Apontamentos para uma história crítica do cordel brasileiro. Rio de Janeiro: Edições Adaga - São Paulo: Editora Luzeiro, 2012.

XXII QUIRINO, Jessier. Prosa morena. Recife: Bagaço, 2001.

XXIII ALBUQUERQUE JÚNIOR, Durval Muniz de. A invenção do nordeste e outras artes. Prefácio de Margareth Rago. 5. ed. São Paulo: Cortez, 2011. p. 139.

XXIV CURRAN, Mark. Retratos do Brasil em Cordel. Cotia, SP: Ateliê Editorial,

2011.

XXV MAgAlHÃES, Agamenon. O Nordeste Brasileiro. Recife: Secretaria Estadual de Educação e Cultura.

Departamento de Cultura. Governo de Pernambuco, 1970.

XXVI MAGALHÃES, Agamenon. O Nordeste Brasileiro. Recife: Secretaria Estadual de Educação e Cultura.

Departamento de Cultura. Governo de Pernambuco, 1970. p. 81.

XXVII MAGALHÃES, Agamenon. O Nordeste Brasileiro. Recife: Secretaria Estadual de Educação e Cultura.

Departamento de Cultura. Governo de Pernambuco, 1970. p. 60.

XXVIII PESAVENTO, Sandra Jatahy. História \& história cultural. 2. Edição. Belo Horizonte: Autêntica, 2012.

XXIX PESAVENTO, Sandra Jatahy. História \& história cultural. 2. Edição. Belo Horizonte: Autêntica, 2012. p. 40.

Cadernos do Tempo Presente, São Cristóvão-SE, v. 10, n. 01, p. 25-36, jan./jul. 2019| http://www.seer.ufs.br/index.php/tempo 


\section{A REPRESENTAÇÃO DO SERTÃO E O "ESPAÇO DA SAUDADE" NA POÉTICA DE JESSIER QUIRINO}

\section{THAÍS DUARTE SILVÉRIO E CRISTIANO CEZAR GOMES DASILVA}

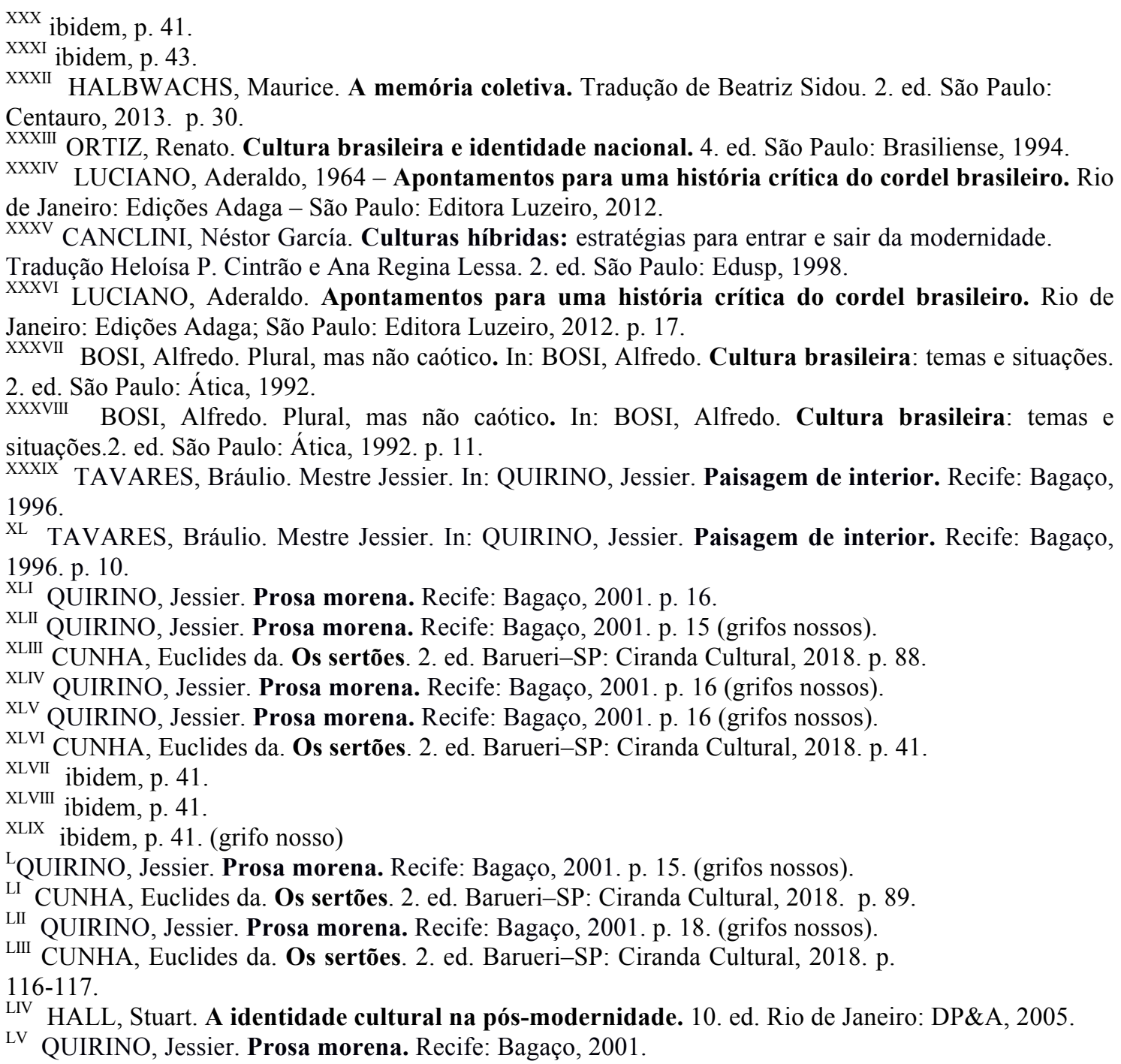

\section{Referências}

ALBUQUERQUE JÚNIOR, Durval Muniz de. A invenção do Nordeste e outras artes. Prefácio de Margareth Rago. 5. ed. São Paulo: Cortez, 2011.

BOSI, Alfredo. Plural, mas não caótico. In: BOSI, Alfredo. Cultura brasileira: temas e situações.2. ed. São Paulo: Ática, 1992.

CANCLINI, Néstor García. Culturas híbridas: estratégias para entrar e sair da modernidade. Tradução Heloísa P. Cintrão e Ana Regina Lessa. 2. ed. São Paulo: Edusp, 1998.

CUNHA, Euclides da. Os sertões. 2. ed. Barueri-SP: Ciranda cultural, 2018.

CURRAN, Mark. Retratos do Brasil em Cordel. Cotia-SP: Ateliê Editorial, 2011. 


\section{A REPRESENTAÇÃO DO SERTÃO E O "ESPAÇO DA SAUDADE" \\ NA POÉTICA DE JESSIER QUIRINO \\ THAÍS DUARTE SILVÉRIO E CRISTIANO CEZAR GOMES DASILVA}

DIÉGUES JÚNIOR, Manuel. Ciclos Temáticos da Literatura de Cordel. Maceió: Imprensa oficial Graciliano Ramos, 2012.

GEERTZ, Clifford. A interpretação das culturas. 1. ed., reimpressão. Rio de Janeiro: LTC, 2008.

HALBWACHS, Maurice. A memória coletiva. Tradução de Beatriz Sidou. 2. ed. São Paulo: Centauro, 2013.

HALL, Stuart. A identidade cultural na pós-modernidade. 10. ed. Rio de Janeiro: DP\&A, 2005.

LUCIANO, Aderaldo. Apontamentos para uma história crítica do cordel brasileiro. Rio de Janeiro: Edições Adaga; São Paulo: Editora Luzeiro, 2012.

MAGAlHÃES, Agamenon. O Nordeste Brasileiro. Recife: Secretaria Estadual de Educação e Cultura. Departamento de Cultura. Governo de Pernambuco, 1970.

ORTIZ, Renato. Cultura brasileira e identidade nacional. 4. ed. São Paulo: Brasiliense, 1994.

PESAVENTO, Sandra Jatahy. História \& história cultural. 2. ed. Belo Horizonte: Autêntica, 2012.

QUIRINO, Jessier. Prosa morena. Recife: Bagaço, 2001.

TAVARES, Bráulio. Mestre Jessier. In: QUIRINO, Jessier. Paisagem de interior. Recife: Bagaço, 1996. 